\title{
O OBSERVATÓRIO SOCIAL COMO EXERCÍCIO DE DEMOCRACIA E SUA INTERFACE COM A LEGISLAÇÃO AMBIENTAL
}

\author{
Valéria Giumelli Canestrini ${ }^{1}$ \\ Denise Schmitt Siqueira Garcia ${ }^{2}$
}

\begin{abstract}
RESUMO: A pesquisa expõe o instituto Democracia e o exercício da cidadania, nas formas de participação popular, como o observatório social, e a importância deste para a lisura dos procedimentos de licenciamentos urbanos-ambientais, fundado na sustentabilidade. Justificase pela necessidade acadêmica de reavivar a democracia e seus objetivos, enfatizando que os observatórios sociais podem ser efetivos na fiscalização da legislação ambiental para garantir direitos socioambientais nas políticas públicas. Elegeu-se o método dedutivo, a técnica bibliográfica. Conclui-se que o exercício da democracia pela cidadania nos observatórios sociais, sob o princípio da sustentabilidade, faz valer a vontade popular na tomada de decisões.
\end{abstract}

PALAVRAS-CHAVE: democracia; cidadania; sustentabilidade; observatório social; direito urbano-ambiental.

\begin{abstract}
The research exposes the Democracy Institute and the exercise of citizenship, in the forms of popular participation, such as the social observatory, and its importance for the correctness of urban-environmental licensing procedures, based on sustainability. It is justified by the academic need to revive democracy and its goals, emphasizing that social observatories can be effective in monitoring environmental legislation to ensure social and environmental rights in public policies. The deductive method, the bibliographic technique, was chosen. It is concluded that the exercise of democracy by citizenship in social observatories, under the principle of sustainability, asserts the popular will in decisionmaking.
\end{abstract}

Key words: democracy; citizenship; sustainability; social observatory; urban-environmental law.

\section{Introdução}

Escrever sobre democracia atualmente, ainda é um grande desafio. Um sistema de

\footnotetext{
${ }^{1}$ Mestranda em Direito pela Universidade do Vale do Itajaí (Univali). Especialista em Direito Civil e Processual Civil pelo Centro Universitário Leonardo Da Vinci (UNIASSELVI). Especialista em Direito Ambiental pelo Centro Universitário Leonardo Da Vinci (UNIASSELVI). Promotora de Justiça no Ministério Público do Estado de Rondônia. E-mail: vcanestrini97@gmail.com

${ }^{2}$ Doutora pela Universidade de Alicante na Espanha. Professora do Programa de Pós-Graduação Stricto Sensu em Ciência Jurídica da UNIVALI - PPCJ. Mestre em Direito Ambiental pela Universidade de Alicante Espanha. Mestre em Ciência Jurídica. Especialista em Direito Processual Civil. Membro do grupo de pesquisa "Estado, Direito Ambiental, Transnacionalidade". Advogada. denisegarcia@univali.br
} 
governo em que, a princípio, bastaria ser conceituado como aquele em que o povo dita as normas e que, ao se analisar os diferentes períodos da história e diversos pensadores, não é tão simples, mas sim, de uma complexidade enorme, em que se idealiza a efetiva participação social e a concretização da vontade popular nas decisões do Estado.

Sem descuidar do princípio da sustentabilidade, o artigo tem como problemática a verificação de que se o observatório social é uma forma de exercício de democracia, pela participação popular atuante na fiscalização do cumprimento da legislação ambiental e na lisura dos procedimentos de licenciamentos urbanos e ambientais e para resguardar os direitos socioambientais.

O que se objetiva com o trabalho é analisar o instituto da Democracia e suas modificações ao longo da história, seus elementos e objetivos, como a cidadania e a participação popular. Dessa forma, pretende-se ainda, mostrar a organização identificada nos observatórios sociais, sendo estes, formas de exercício de participação da sociedade, que visam a lisura e a efetividade na aplicação das políticas públicas onde se insere a ambiental de forma ampla, tornando-se uma efetiva forma de inclusão nas decisões dos poderes públicos que devem sempre ser fundadas no princípio da sustentabilidade.

A pesquisa tem sua importância acadêmica diante da reflexão dos institutos de Teoria Geral do Estado e a complexidade desses conceitos operacionais de democracia, cidadania e participação popular no desenrolar da História. A importância social é identificada na análise da organização dos observatórios sociais como forma de participação popular efetiva nas decisões públicas para a garantia da atuação de comportamentos éticos e sustentáveis na observância das normas.

O trabalho se estruturou da seguinte forma: na primeira parte são analisados, de forma inaugural, conceitos básicos que circundam a definição de Democracia, cidadania e participação popular, de forma panorâmica no desenrolar da História e diversos pensadores.

Na segunda parte, a análise recai sobre o conceito operacional de observatório social, o surgimento e finalidades, diante da realidade social contemporânea, sendo forma efetiva de participação popular. Por fim, na terceira parte, são delineados argumentos no sentido de constatar-se a possibilidade de atuação dos observatórios sociais na fiscalização da aplicação das normas urbano-ambientais, legislação ambiental de forma ampla, como exercício de cidadania ambiental, com fundamento no princípio da sustentabilidade.

No que se refere aos aspectos metodológicos (PASOLD, 2011, p. 81), foi eleito o 
método dedutivo, a utilização da técnica da Categoria, da técnica da Pesquisa Bibliográfica, para colher o material histórico-teórico necessário para a análise dos dados obtidos.

\section{Da democracia, cidadania e participação popular}

A democracia como regime de governo está estampada no art. $1^{\circ}$ e parágrafo único da Constituição Federal de 1988 do Brasil, constituindo o Estado Democrático de Direito que tem, dentre seus fundamentos, a cidadania, onde "todo o poder emana do povo, que o exerce por meio de representantes eleitos ou diretamente". Essa foi a escolha dos representantes eleitos em maioria pelo povo brasileiro. Escolha essa, orientada por inúmeros fatos históricos e delineada no pensamento de vários filósofos, historiadores e doutrinadores, esclarecendo-se que nem sempre com o significado admitido no sentido expresso na norma constitucional.

Ao tratar da categoria Democracia, Paulo Márcio Cruz (2013, p. 41 e 58) informa que o conceito que teria sido utilizado por Heródoto, no período antigo, foi considerado, por Aristóteles numa visão negativa, já que esse governo popular, estava, ao lado da tirania e da oligarquia, como um tipo de governo corrupto, na medida em que, esse governo popular era instalado para a satisfação de interesses particulares dos muitos que o tinham nas mãos, pois dos detentores desse poder, os pobres estavam excluídos já que não seriam capazes de defenderem interesses voltados para o bem comum.

$\mathrm{Na}$ Grécia, a democracia foi um sistema político de governo diretamente exercido de forma popular, pela assembleia popular, embora com restrições na cidadania, mas que tomava todas as decisões de caráter legislativo, executivo e judiciário. Em Roma, era exercido um governo misto, com poderes de um grupo popular e outro grupo escolhido por classes superiores. A cidadania era natural, inerente ao indivíduo que detinha posses ("socialmente emancipado"), não havia separação entre comunidade civil e comunidade política. (BADIA, 1996, p. 182).

Já no século XIX, democracia, estava ligada à relação Estado e sociedade, sendo que o poder político, considerado como do povo, não estava limitado por classes ou gênero e tinha por objetivo que os cidadãos controlassem, interviessem e definissem as decisões, para a concretude da vontade popular. Nesse ponto, passa-se à organização da democracia representativa - governantes e governados -, em que a soberania popular é delegada aos eleitos representantes do povo, com separação por órgãos e funções como: legislativa, executiva e judiciária (diferindo da democracia direta exercida pelos gregos e romanos). 
(BADIA, 1996, p. 183).

As origens da democracia representativa e direta tem por base ainda a relação entre igualdade política e igualdade social. Nos governos previamente ao século XIX, a democracia assumiu várias formas de representatividade, como o parlamentarismo e a intervenção da monarquia, além da ideia absolutista de que o monarca seria a personificação de todo o sistema e todas as funções (legislativo, executivo e judiciário), como exemplificado em países europeus.

Por certo que a democracia representativa que se conhece foi fruto muito mais da transformação de uma sociedade agrária para uma sociedade industrial e do liberalismo, do que de concepções de sociedade igualitária. (BADIA, 1996, p.187).

A partir de John Stuart Mill o liberalismo democrático passou a introduzir direitos civis, políticos, sociais, econômicos e culturais com base na igualdade de oportunidades, a fim de justificar o autogoverno moral do indivíduo cidadão, afastando-se das teorias jusnaturalistas, mas com base normativa a partir de então. (BADIA, 1996, p.193).

O Estado (republicano-democrático) deixou de apenas assegurar o mínimo necessário aos indivíduos e passou-se ter a democracia como um regime formal de governo, para um Estado em que deveria garantir bens coletivos para a liberdade dos indivíduos, com igualdade social, evitando vícios de vontades, assumindo assim, a democracia, um aspecto substancial ao formal já existente.

Pelo liberalismo democrático, a democracia seria o regime ideal, ou seja, aquele que mais considera a natureza humana e que é capaz de atender às suas necessidades. (CRUZ, 2013, p. 41-58)

Para José Afonso da Silva, o conceito de Democracia é mais abarcante do que o conceito de Estado Democrático de Direito, realizado no período do liberalismo:

\footnotetext{
A democracia, como realização de valores (igualdade, liberdade e dignidade da pessoa) de convivência humana, é conceito mais abrangente que o de Estado de Direito, que surgiu como expressão jurídica da democracia liberal. Seu conceito é tão histórico como o de democracia, e se enriquece de conteúdo com o evolver dos tempos. A evolução histórica e a superação do liberalismo, a que se vinculou o conceito de Estado de Direito, colocam em debate a questão da sua sintonia com a sociedade democrática. (SILVA, 1988)
}

No século XX, observando-se vários países em que a democracia permaneceu, como França, Estados Unidos, Suíça, Reino Unido, há uma escalada de realidades ligadas às 
situações de garantias dos direitos políticos e dos direitos civis. Dessa forma, Miguel Caminal Badia propõe o estudo da democracia nesse período da História em três categorias: sociológicas, econômicas e filosóficas. (BADIA, 1996, p. 197).

Segundo explicado e exemplificado por Miguel Caminal Badia (1996, p. 197 e 226), ao descrever as três categorias de democracia, a categoria sociológica se preocupa em analisar a distribuição do poder (ex. Joseph A. Schumpeter que entendia que o povo assim como pode escolher seus governantes também pode retirá-los ao exercer o voto; Dahl que entendia que o pluralismo estava presente nas diferentes representações sociais, cabendo ao Estado, a mediação ditando "as regras do jogo"); a econômica se preocupa com as normas de decisão e a composição analítica das mesmas (ex. Downs, com a teoria econômica da democracia de que os grupos agiam por seus próprios interesses - poder, prestígio e se manter no governo - e não por um bem comum); e a filosófica que está preocupada com os fins da democracia, no modelo democrata-republicano; com o bem comum resguardado pelo Estado; com análise das formas de participação popular e o acréscimo de outras, além das questões de justiça e melhor governabilidade por parte das instituições e das sociedade atuais, que se apresentam de forma complexa (ex. John Rawls para quem haveria uma noção pública de justiça, com base em princípios de distribuição de vantagens sociais e econômicas com garantia de direitos e deveres; e Dworkin com seu liberalismo igualitário, considerando a igualdade nos seus aspectos formal e material, com a distribuição de riquezas para o bem estar social seguindo uma integração ética).

Importante destacar, além desses pensadores da democracia do século $\mathrm{XX}$, a teoria comunicativa de Jürgen Habermas para quem a democracia seria "la forma política derivada de un libre proceso comunicativo dirigido a lograr acuerdos consensuales en la toma de decisiones colectivas" (BADIA, 1996, p. 228) ou seja, o regime democrático precisa se preocupar se todos os afetados pelas decisões políticas puderam ser ouvidos e fazerem parte de forma ampla do que resultou em uma decisão coletiva em um espaço de diálogos em que vença a melhor argumentação.

Por certo, que a democracia direta ainda prevaleceu em institutos como o referendo e o plebiscito, nos Estados detentores de Constituições. E também, a democracia é o regime de governo dos Estados contemporâneos, não podendo desvincular o conceito operacional de cidadania contido dentro da democracia.

Não há democracia sem a participação popular, sem o exercício da cidadania, seja de 
forma direta, seja na escolha de seus representantes, daqueles que defenderão os interesses para a completude de uma democracia social que deve ter por objetivo a busca do bem comum, o bem da coletividade.

Nesse ponto, Alain Touraine (1996, p. 164) defende que a democracia deve acontecer às claras, com a participação da maior quantidade de cidadãos (efetiva atuação do sujeito) para a garantia social da implementação o das demandas sociais da maioria, evitando o arbítrio e a utilização de meios ocultos.

Ao analisar o contexto da democracia exercida, principalmente na Itália, fazendo uma reflexão sobre os novos caminhos da democracia, Norberto Bobbio, na obra, "O futuro da Democracia” (BOBBIO, 2000, p. 17), expõe que a democracia seria uma forma de governo, já determinada por normas procedimentais, em que a mais ampla participação da maioria deve ser proporcionada, para a formação de decisões para a coletividade.

Mas o processo de democratização estaria sempre tendente a ascender, pois além da democracia representativa e da democracia direta, que são facilmente identificáveis, passaria da democracia política para a democracia social, em que os indivíduos se movimentassem de acordo com seus papéis exercidos em sociedade nas várias instituições sociais (família, escola, igreja, local de trabalho) para que nessas também as decisões respeitem e efetivem o desejo coletivo. (BOBBIO, 1996, p. 04)

E nesse sistema de participação é que a cidadania deve ser exercida com a consciência de participação política coletiva e de defesa de interesses comuns e sociais, para que, por meio do voto, pela possibilidade de escolher e ser escolhido, haja uma vontade livre com a adequada escolha dos dirigentes, dos governantes. É a "bandeira da soberania, da igualdade e da justiça social.” (BONAVIDES, 2008, p. 14).

Contemporaneamente, Georg Sorensen escreve sobre a democracia, sua evolução nos diversos continentes e a prospecção de futuro com o processo de democratização, como modelo propulsor de paz, prosperidade e bem-estar da humanidade: Democracy is a form of government in which the people rule means a lot what democracy actually is. It comes from two Greek words demos (people) and kratos (rule). The definition 'rule by the people' may sound straightforward, but it raises a number of complex issues. (SORENSEN, 2007, p. 3).

Segundo o autor mencionado, democracia não é um conceito estanque, mas dinâmico que muda e se refaz em vários países e fases históricas de acordo com inúmeras variantes, o que movimenta o processo de democratização, com a atuação dos atores envolvidos numa 
interação entre as realidades sociais, econômicas e culturais (democracia participativa ${ }^{3}$ ). (SORENSEN, 2007, p. 53).

O princípio democrático, com base na representatividade, dá lugar à formação de estruturas em que os cidadãos participem diretamente, como a formação de entidades de representação, o voto nas eleições periódicas, o pluralismo partidário, o sistema de separação dos poderes, entre outros, com a efetiva garantia de espaços de processos deliberativos em que a liberdade impere e que desses decorra a legitimidade das ações nas decisões da esfera pública. (ANDRADE, 2020).

Essa democracia participativa que adentra ao século XXI, é a que se depara com o cenário dos blocos econômicos, num espaço transnacional global, em que os interesses econômicos, por vezes, suplantam os interesses sociais, e relegam aos indivíduos o papel de consumidores. "Na Democracia Representativa os cidadãos elegem quem vai politicamente decidir. Na Democracia Participativa os cidadãos tomam as decisões políticas" (FERRER; CRUZ, 2021, p. 96-111), que deve ter por base a fraternidade e solidariedade para que as ações coletivas prevaleçam visando fins coletivos nas comunidades, a fim de que a vida em equilíbrio no planeta seja sustentável ao longo do tempo.

\section{A formação e finalidade dos observatórios sociais}

Por ser a democracia um regime que não seja um valor em si mesmo, mas que auxilia na promoção de outros direitos civis e políticos para a participação social, é que permite a formação de entidades como os observatórios sociais que, além de possibilitarem a fiscalização dos atos do poder público, são espaços para que a coletividade expresse as suas demandas permitidas pela janela oferecida pela democracia, com liberdade política, de expressão, de participação e defesa dos direitos humanos. ${ }^{4}$

O exercício da cidadania num espaço democrático de decisões é a participação popular para a legitimidade da criação e aplicação das normas de direito.

\footnotetext{
3 "One crucial elemento in maintaining a democracy, therefore, is the active participation of the population." In: SORENSEN, Georg. Democracy and Democratization- Processes and Prospects in a Changing World (Third Edition); Dilemmas in World Politics Series, Boulder, Colorado: Westview Press, 2007, p. 162.

4 "Democracy does not promise automatic improvement in áreas of life that are not narrowly conected with political freedom; it creates a window of opportunity, a political framework where groups struggling for development and human rights have better possibilities than before for organizing and expressing their demands.” In: SORENSEN, Georg. Democracy and Democratization- Processes and Prospects in a Changing World (Third Edition); Dilemmas in World Politics Series, Boulder, Colorado: Westview Press, 2007, p. 130.
} 
Dessa forma, a inclusão daqueles afetados pelas normas e decisões do poder público relativas aos conflitos diversos, e nesses, os ambientais, é o ideal nesse espaço de democracia, pois só assim essa validade seria garantida pelo exercício da cidadania, sobressaindo-se a vontade popular, a concordância e ciência dos envolvidos e afetados, seria a identificação de que os próprios destinatários das normas, sintam-se os próprios autores destas. (CAVEDON; VIEIRA, 2011).

Seria esse o espaço democrático dos observatórios sociais, comprovando a necessidade de articulação da sociedade civil para que os problemas reais, do mundo da vida, cheguem e sejam discutidos nos espaços públicos políticos e sejam considerados na produção e aplicação das normas para a satisfação das necessidades sociais. Que sejam o reflexo dos interesses e necessidades sociais consideradas com a identificação dos efetivos problemas do mundo real, não como abstração, justamente para que a política e o direito não sejam sistemas fechados, suficientes em si mesmos. (CAVEDON; VIEIRA, 2011)

A opinião formada nos observatórios sociais traz à tona os problemas da periferia, identificando os problemas sociais e concretizando a representação de grupos diversos, como apontado na Teoria da Ação Comunicativa de Habermas, explicada no Dicionário de Filosofia:

\begin{abstract}
Segundo a consideração teorética da comunicação de Habermas sobre a ação social, o que torna possível a ação coordenada é essa capacidade de chegar a um entendimento mútuo sobre alguma coisa (a partir de uma razão que una sem apagar a separação, que ligue sem negar as diferenças, que indique o comum e o compartilhado entre estranhos, sem privar o outro da condição de outro), sendo essa questão novamente conectado a processos abertos de justificação discursiva. (BARRETO, 2009).
\end{abstract}

A ação de diálogos dos sujeitos, na demonstração da realidade social e a consideração no sistema político democrático. O chamado "Horizontal accountability", a organização dos cidadãos de forma a influenciar nas decisões dentro da sua vizinhança, ou seja, no espaço local onde vivem.

Pode-se acrescentar que essa seria a conquista da democracia no espaço do Direito, em que todos possam fiscalizar e analisar as decisões jurídicas, podendo as instituições serem

\footnotetext{
5 "Horizontal accontability is defined by Robert Johansen as the ability of citizens to influence the decisions tha are made in neighboring societies and that directly affect them. It is achieved through democratic international institutions that guarantee rights for global minorities as well as majorities." In: SORENSEN, Georg. Democracy and Democratization- Processes and Prospects in a Changing World (Third Edition); Dilemmas in World Politics Series, Boulder, Colorado: Westview Press, 2007, p. 162.
} 
a todo o tempo reconstruídas. (BORGES, 2021. p. 239 e 265).

Após a Constituição Federal de 1988, pode-se ver mais claramente formas de participação social nas estruturas políticas como os conselhos, e conferências municipais de políticas públicas, audiências públicas e o orçamento participativo. Permitindo as iniciativas de criação dos observatórios sociais.

\begin{abstract}
Nessa interface entre instituições representativa e participativas é possível ampliar a perspectiva de accountability. Entendida em princípio como a "capacidade dos eleitores, individuais ou grupais, de exigir que os representantes expliquem o que fazem (respondam por, sejam responsabilizados ou mesmo punidos pelo que fazem)", também apresenta uma dimensão deliberativa, pois permite a comunicação entre representantes e representados que não se limita ao momento eleitoral por meio da atuação da sociedade civil na esfera pública. (GASPARDO, 2021. p. 65 e 88)
\end{abstract}

Toda a prática dos administradores públicos pode ser fiscalizada pelo povo, tendo em vista que, a arrecadação por meio de tributos, gera a oportunidade, e porque não dizer, o dever de exercício da cidadania de exigir a transparência, a eficiência e a devida responsabilização pela administração desses recursos públicos. E para tanto, o art. 37, parágrafo $3^{\circ}$ da Constituição Federal prevê a regulamentação legal para a participação popular por meio do controle social.

O exercício do controle social por meio de uma cidadania ativa precede de um Estado que expresse por meio de normas essa segurança aos seus cidadãos e de uma sociedade civil organizada, composta por pessoas conscientes do seu papel e da finalidade do exercício dessa cidadania.

No Portal da Transparência do Governo Federal (PORTAL DA TRANSPARÊNCIA DO GOVERNO FEDERAL, 2021) há um espaço para informações sobre o controle social que permite que os cidadãos não esperem que o exercício do voto baste num sistema democrático na escolha de seus representantes. Menciona a importância do acompanhamento das ações dos governantes na proteção do erário, a fim de acompanhar a execução da melhor governança pública, no desenvolvimento das políticas públicas (incluindo as áreas de meio ambiente e urbanismo) e avaliar se os objetivos, os propósitos dos projetos políticos em benefício da coletividade, estejam tendo o resultado esperado e prometido em época eleitoral. É a participação popular que não acaba no voto, mas que tem uma direção a partir deste.

São iniciativas de organização social e participação popular, como o Observatório Social, identificadas em municípios brasileiros, voltadas ao combate da corrupção, ao 
incentivo à cidadania como meio de fiscalização das receitas e despesas públicas, acompanhando os programas governamentais e auxiliando na construção de indicadores de desenvolvimento e qualidade de vida.

O conceito operacional de Observatório Social pode ser encontrado no site do Observatório Social do Brasil:

\begin{abstract}
É um espaço para o exercício da cidadania, que deve ser democrático e apartidário e reunir o maior número possível de entidades representativas da sociedade civil com o objetivo de contribuir para a melhoria da gestão pública.

Cada Observatório Social é integrado por cidadãos brasileiros que transformaram o seu direito de indignar-se em atitude: em favor da transparência e da qualidade na aplicação dos recursos públicos. São empresários, profissionais, professores, estudantes, funcionários públicos (exceto os que integrem a esfera de atuação do observatório específico) e outros cidadãos que, voluntariamente, entregam-se à causa da justiça social. (OBSERVATÓRIO SOCIAL DO BRASIL, 2021).
\end{abstract}

Esta iniciativa surgiu contemporânea a reunião de um grupo de lideranças em Maringá, no Estado do Paraná, em 2003, para a fiscalização da aplicação do dinheiro público e passou a tratar de diversos temas ligados àquela comunidade, como violência, trânsito, educação fiscal.

A partir desse passo, criaram o Movimento de Cidadania Fiscal do qual nasceu o Instituto de Cidadania Fiscal que posteriormente criou a ONG Sociedade Eticamente Responsável (SER), a qual desenvolveu o Observatório Social de Maringá/PR. Desse modelo de Observatório Social foi criado um modelo padronizado para divulgação e promoção da disseminação e estruturação de outros nos demais Estados do Brasil. (MATOS, 2018, p. 84$85)$.

O Observatório Social nasce como pessoa jurídica de direito privado, sem fins lucrativos, com um estatuto regulamentador, configurando-se uma Organização da Sociedade Civil de Interesse Público (OSCIP), regido pela Lei n. 9.790/99. (MATOS, 2018, p. 86)

Algumas das ações do Observatório Social podem ser mencionadas: a fiscalização dos processos licitatórios, o resguardo dos princípios da transparência e publicidade, o incentivo a maior participação social para fiscalizar e exigir mudanças quando necessárias e viabilizar a prevalência de práticas sustentáveis, dialogando com os demais órgãos de controle e fiscalização. (MATOS, 2018, p. 15).

Nessa organização, concretiza-se o exercício da cidadania que pode influenciar as escolhas políticas nas políticas públicas, resguardando a observância dos princípios da Administração Pública, dentre estes, o da sustentabilidade. 


\title{
4 A possibilidade de atuação dos observatórios sociais na fiscalização da aplicação das normas urbano-ambientais como exercício de cidadania ambiental
}

O movimento ambiental, com a mobilização dos cidadãos foi a essência do reconhecimento e garantida do Direito Ambiental como tal, sendo assim, democrático por sua natureza. Os princípios da informação e participação concretizam o princípio democrático no direito ambiental, além do princípio da publicidade:

\begin{abstract}
O princípio democrático é aquele que assegura aos cidadãos o direito pleno de participar na elaboração das políticas públicas ambientais. No sistema constitucional brasileiro, tal participação faz-se de várias maneiras diferentes. A primeira delas consubstancia-se no dever jurídico de proteger e preservar o meio ambiente; a segunda, no direito de opinar sobre as políticas públicas, através da participação em audiências públicas, integrando órgãos colegiados etc. Há ainda, a participação que ocorre através da utilização de mecanismos judiciais e administrativos de controle dos diferentes atos praticados pelo Executivo, tais como as ações populares, as representações e outros. Não se pode olvidar também, as iniciativas legislativas que podem ser patrocinadas pelos cidadãos. (ANTUNES, 2004, p. 33).
\end{abstract}

Sendo o Observatório Social uma forma de democracia participativa, uma forma de controle social, a fim de fiscalizar a atuação dos atos dos poderes públicos para o resguardo do patrimônio público, dos direitos sociais e de práticas sustentáveis, caracteriza-se como uma via de exercício de cidadania ambiental.

A sustentabilidade é o princípio que deve nortear os atos dos governantes, representantes da coletividade, para a garantia de práticas equilibradas que permitam a continuidade da vida no planeta e assim nas áreas: ambiental, social e econômica.

Para Juarez Freitas, a sustentabilidade (2012, p. 15-16):

[...] consiste em assegurar, de forma inédita, as condições propícias ao bem-estar físico e psíquico no presente, sem empobrecer e inviabilizar o bem-estar no amanhã, razão pela qual implica o abandono, um a um, dos conceitos insatisfatórios de praxe. Cessa - ou tende a cessar - o barbarismo irracional dos que apostam no crescimento econômico pelo crescimento, nas perdas irreparáveis de biodiversidade e na devastação da biosfera como método.

A Comissão Mundial sobre Meio Ambiente e Desenvolvimento, pela ONU, no Relatório Brundtland, de 1987, conceituou que "O desenvolvimento sustentável é aquele que atende as necessidades do presente sem comprometer a possibilidade de as gerações futuras atenderem as suas próprias necessidades. " (ONU BRASIL, 2001) 
Diante desse cenário, as práticas econômicas de mercado não podem descuidar da preocupação com o meio ambiente e o equilíbrio social. As formas de governança sustentável devem estar presentes no planejamento de empresas públicas e privadas, formalizadas na sustentabilidade corporativa. (SOUZA, 2016, p. 245-262).

O clamor nas ações governamentais deve ser de observância do princípio da sustentabilidade, nesse sentido como exposto por Alves e Canestrini:

\begin{abstract}
A sustentabilidade, considerada nas suas dimensões, com o atendimento da geração atual e das futuras gerações, em vários documentos normativos de direito ambiental, foi considerada pela comunidade internacional, uma saída para a manutenção de um meio ambiente, seja natural ou urbano, de forma equilibrada. E esta institui a solidariedade, inserida no conceito maior de fraternidade, como questão ética, a fim de que todos tenham a sensação de pertencimento, de inclusão e de responsabilidade pela preservação. (ALVES; CANESTRINI, 2020, p. 205).
\end{abstract}

Como forma de exigir o cumprimento do princípio da sustentabilidade e como limitação de atividades potencialmente nocivas aos meio ambiente, é que são exigidas as licenças, que, para o Ministério do Meio Ambiente, o licenciamento ambiental é um instrumento da Política Nacional de Meio Ambiente, estabelecida pela Lei $n^{\circ}$ 6938, de 31 de agosto de 1981, que tem como objetivo a preservação, melhoria e recuperação da qualidade ambiental propícia à vida, visando assegurar condições ao desenvolvimento socioeconômico, aos interesses da segurança nacional e à proteção da dignidade da vida, além de ter previsão constitucional, no artigo 225, parágrafo primeiro, inciso IV, para obras potencialmente causadoras de grande degradação ambiental. ${ }^{6}$

O licenciamento como procedimento administrativo é definido pela Resolução n. 237/97 do CONAMA (Conselho Nacional do Meio Ambiente), no seu artigo $1^{\circ}$, I, que prevê:

Licenciamento Ambiental: procedimento administrativo pelo qual o órgão ambiental competente licencia a localização, instalação, ampliação e a operação de empreendimentos e atividades utilizadoras de recursos ambientais, consideradas efetiva ou potencialmente poluidoras ou daquelas que, sob qualquer forma, possam causar degradação ambiental, considerando as disposições legais e regulamentares e as normas técnicas aplicáveis ao caso. (CONAMA, 1997)

O licenciamento ambiental, como poder de polícia do Estado, avalia os impactos de uma atividade, nas áreas multidisciplinares, abarcando inúmeros princípios de direito

\footnotetext{
${ }^{6}$ BRASIL. Ministério do Meio Ambiente. Programa Nacional de Licenciamento Ambiental - PNLA. O que é licenciamento. Disponível em < http://pnla.mma.gov.br/o-que-e-licenciamento-ambiental>. Acesso em: 08 de jan. 2021.
} 
ambiental.

A fiscalização popular de todo esse procedimento para que as regras de integridade sejam respeitadas, bem como a aplicação das melhores técnicas disponíveis, visando o bem de uma determinada coletividade, fundado no princípio da sustentabilidade, pode ser exercida pelo Observatório Social dentre as ações a que lhe cabem.

O respeito às normas de práticas sustentáveis também deve ocorrer nos processos licitatórios, devendo o Observatório Social, não descuidar da observância da lei de licitações, nesses procedimentos administrativos, como norma de proteção sustentável, garantindo o acompanhamento dos processos licitatórios pelos cidadãos, como dispõe a Lei de Licitações n. $8.666 / 93 .^{7}$

A ordem urbanística e suas licenças devem estar sob a vigilância do observatório social, já que nesses procedimentos pode ocorrer a prevalência do lado econômico frente ao social e ambiental, na troca de favores para a liberação de grandes empreendimentos empresariais.

O Estatuto das Cidades, Lei. 10.257, de 10 de julho de 2001, prevê a garantia legal do "direito a cidades sustentáveis", incluindo-se diversos direitos sociais, tais como moradia digna, saneamento básico adequado (saúde pública), ao trabalho, ao lazer, dentre outros, para as presentes e futuras gerações, sendo assim, intergeracional, prevendo mecanismos de participação e controle social.

Tendo o Observatório Social como um de seus objetivos específicos a apresentação de propostas para o desenvolvimento de ações e estudos, que impulsionem inclusive mudança social fundamental e mudança na gestão de recursos públicos nas diversas áreas (MATOS, 2018, p. 93), como saúde, educação, licitação, por certo que é um instrumento essencial de participação democrática por excelência, para fiscalizar a lisura dos procedimentos de licenciamentos urbano- ambientais e a observância do princípio da sustentabilidade, bem

\footnotetext{
7 “Art. $3^{\circ}$ A licitação destina-se a garantir a observância do princípio constitucional da isonomia, a seleção da proposta mais vantajosa para a administração e a promoção do desenvolvimento nacional sustentável e será processada e julgada em estrita conformidade com os princípios básicos da legalidade, da impessoalidade, da moralidade, da igualdade, da publicidade, da probidade administrativa, da vinculação ao instrumento convocatório, do julgamento objetivo e dos que lhes são correlatos. (...) Art. $4^{\circ}$ Todos quantos participem de licitação promovida pelos órgãos ou entidades a que se refere o art. $1^{\circ}$ têm direito público subjetivo à fiel observância do pertinente procedimento estabelecido nesta lei, podendo qualquer cidadão acompanhar o seu desenvolvimento, desde que não interfira de modo a perturbar ou impedir a realização dos trabalhos." In: BRASIL. Lei n. 8.666, de 21 de julho de 1993. Regulamenta o art. 37, inciso XXI, da Constituição Federal, institui normas para licitações e contratos da Administração Pública e dá outras providências. Disponível em: $<$ http://www.planalto.gov.br/ccivil_03/leis/1866 6cons.htm> Acesso em: 11 de jan. 2021.
} 
como para estimular a educação e conscientização de proteção ambiental.

\section{Considerações Finais}

O presente artigo decorreu de uma pesquisa que vislumbrou o desenvolvimento do conceito de democracia ao longo dos períodos históricos chegando ao tempo contemporâneo com a identificação de uma democracia participativa que, pode se apresentar de várias formas, sendo uma delas a organização da sociedade civil por meio do Observatório Social.

O princípio democrático faz parte do conjunto de normas de proteção ambiental, sendo aquele que garante aos cidadãos a informação sobre as diversas intervenções e impactos seja no meio ambiente natural como urbano e assegura de uma forma livre os meios que possibilitam aos mesmos cidadãos a busca pela efetividade desse direito, bem como da proteção ambiental, fundada no princípio da sustentabilidade.

A democracia não pode ser considerada como concedida, mas como decorrente de uma prática pedagógica de conscientização e estímulo à organização social por várias iniciativas populares que promovam a informação popular e o acompanhamento das propostas de governo, renovando a educação para a cidadania.

Da conjugação de um exercício de cidadania por meio do Observatório Social e do princípio democrático ambiental, conclui-se que essa organização social é um instrumento possível para fiscalizar a lisura dos procedimentos de licenciamentos urbano-ambientais, com a devida observância do princípio da sustentabilidade, bem como para estimular a educação e conscientização da proteção ambiental.

\section{Referências}

ALVES, Jaime Leonidas Miranda; CANESTRINI, Valéria Giumelli. A Proteção ao Meio Ambiente como Questão Transnacional: Solidariedade e Fraternidade como Novos Pontos de Partida. In: Globalização e Transnacionalidade (recurso eletrônico). Org. Carla Piffer, Denise S. S. Garcia. Itajaí, Univali, 2020. P. 205-220.

ANDRADE, Marcela Coelho. A Legitimidade do Direito no Contexto dos Processos de Validação Discursiva e da Democracia. Disponível em < https://periodicos.ufjf.br/index.php/ csonline/article/view/17573>. Acesso em: 14 dez. 2020.

ANTUNES, Paulo de Bessa. Direito Ambiental. 7 ed; Rio de Janeiro: Lumen Juris, 2004.

BADIA, Miguel Caminal et al. Manual de ciência política. Madrid:Tecnos, 1996. 
BARRETO, Vicente de Paulo (coord.). Dicionário de Filosofia do Direito. Ed. Unisinos; Renovar. São Leopoldo/RS, Rio de Janeiro/RJ. 2009.

BOBBIO, Norberto. O Futuro da Democracia. Trad. de Marco Aurélio Nogueira. $11^{\text {a }}$ ed. São Paulo: Paz e Terra, 2000.

BONAVIDES, Paulo. Democracia Participativa - por um Direito Constitucional de luta e resistência, por uma Nova Hermenêutica por uma politização da legitimidade. 3 ed; São Paulo: Malheiros, 2008.

BORGES, Fábio Leonel. Procedimentalidade Democrática e Princípio do Discurso como Garantias Constitucionais. Revista da Faculdade de Direito de Uberlândia v. 40: 239-265, 2012. Disponível em < http://www.seer.ufu.br/index._php/revistafadir/article/view/18554>. Acesso em: 09 jan. 2021.

BRASIL. Conselho Nacional do Meio Ambiente - CONAMA. Resolução n. 237, de 19 de dezembro de 1997. Disponível em < http://www2.mma.gov.br/port/co nama/res/res97/ res23797.html>. Acesso em: 08 jan. 2021.

BRASIL. Constituição da República Federativa do Brasil de 1988. Texto consolidado até a EC n. 91, de 2016. Portal da Presidência da República: Constituição. Brasília, DF. Disponível em: <http://www.planalto.gov.br/ ccivil_03 /constituicao/constituicaocompilado.htm>. Acesso em: 06 jan. 2021.

BRASIL. Lei n. 8.666, de 21 de julho de 1993. Regulamenta o art. 37, inciso XXI, da Constituição Federal, institui normas para licitações e contratos da Administração Pública e dá outras providências. Disponível em: <http://www.planalto.gov.br/ccivil_03/leis/18666 cons.htm> Acesso em: 11 jan. 2021.

BRASIL. Lei n..$^{\circ}$ 10.257, de 10 de julho de 2001. Regulamenta os arts. 182 e 183 da Constituição Federal, estabelece diretrizes gerais da política urbana e dá outras providências. Disponível em: <http://http://www.planalto.gov.br/ccivil _03/leis/ leis_ 2001/110257.htm:>. Acesso em: 08 jan. 2021.

BRASIL. Lei n. ${ }^{\circ}$ 6938, de 31 de agosto de 1981. Dispõe sobre a Política Nacional do Meio Ambiente, seus fins e mecanismos de formulação e aplicação, e dá outras providências. Disponível em: <http://www.planalto.gov.br/ccivil_ 03/leis/16938.htm>. Acesso em: 08 jan 2021.

BRASIL. Ministério do Meio Ambiente. Programa Nacional de Licenciamento Ambiental PNLA. O que é licenciamento. Disponível em < http://pnla.mma.gov.br/o-que-e-licen ciamento-ambiental>. Acesso em: 08 jan. 2021.

CAVEDON, F. S.; VIEIRA, R. S. A política jurídica e o direito socioambiental. Novos Estudos Jurídicos (UNIVALI), v. 1, p. 1, 2011. 
CRUZ, Paulo Márcio. Democracia e cidadania. Argumenta Journal Law, Jacarezinho - PR, n. 4, p. 41-58, jan. 2013. ISSN 2317-3882. Disponível em: <http://seer.uenp.edu.br/index.php/ argumenta/article/view/30/31>. Acesso em: 07 jan. 2021.

FERRER, Gabriel Real; CRUZ, Paulo Márcio. Os novos cenários transnacionais e a democracia assimétrica. Revista de Estudos Constitucionais, Hermenêutica e Teoria do Direito (RECHTD) 2(2): 96-111 julho-dezembro 2010. Disponível em < http://revistas.unisinos.br/ index.php/RECHTD/article/ view/442>. Acesso em: 10 jan. 2021.

FREITAS, Juarez. Sustentabilidade: Direito ao futuro. Belo Horizonte: editora, 2012.

GASPARDO, M. Democracia participativa e experimentalismo democrático em tempos sombrios. Estudos Avançados, [S. l.], v. 32, n. 92, p. 65-88, 2018. Disponível em: https://www.revistas.usp.br/eav/article/view/146438. Acesso em: 10 jan. 2021.

MATOS, Ellen Cristina de. Observatório Social: Instrumento de accountability e transparência da gestão dos recursos públicos. Brasília, Print Impressões Inteligentes, 2018, p. 93.

OBSERVATÓRIO SOCIAL DO BRASIL (OSB). Disponível em: <https://osbrasil. org.br/>. Acesso em: 11 jan. 2021.

ONU BRASIL. Comissão Mundial sobre Meio Ambiente e Desenvolvimento. Nosso Futuro Comum. 2. ed. Rio de Janeiro: FGV, 2001.

PASOLD, Cesar Luiz. Metodologia da Pesquisa Jurídica: teoria e prática. Florianópolis: Conceito Editorial, 2011.

PORTAL DA TRANSPARÊNCIA DO GOVERNO FEDERAL. Controle Social. Brasília: 2021. Disponível em: <http://www.portaldatransparencia.gov.br/pagina-interna/603399controle-social>. Acesso em: 11 jan. 2021.

SILVA, José Afonso da. O Estado Democrático de Direito. R. Dir. Adm., Rio de Janeiro, 173: $15-34$ jul/set. 1988. Disponível em < http://bibliotecadigital.fgv. br/ojs/index.php/rda/article/ view/45920/44126>. Acesso em: 09 jan. 2021.

SORENSEN, Georg. Democracy and Democratization- Processes and Prospects in a Changing World (Third Edition); Dilemmas in World Politics Series, Boulder, Colorado: Westview Press, 2007.

SOUZA, Maria Cláudia da Silva Antunes de. Sustentabilidade corporativa: uma iniciativa de cunho social transformando o meio ambiente. Revista Jurídica. Uni Curitiba. vol. 04, $\mathrm{n}^{\circ} .45$, Curitiba, 2016. pp.245- 262. Disponível em: < http://re vista.unicuritiba.edu.br/index.php/Ver Jur/article/view/1803/1183>. Acesso em: 08 jan. 2021.

TOURAINE, Alain. O que é a democracia? Trad. Guilherme João de Freitas Teixeira. 2 ed. Petrópolis: Vozes, 1996. 